\title{
No evidence for innate differences in tadpole behavior between natural, urbanized, and invasive populations
}

\author{
Max Mühlenhaupt ${ }^{1,2}$ (D) James Baxter-Gilbert ${ }^{2}$ (D) $\cdot$ Buyisile G. Makhubo $^{3}$ (D) Julia L. Riley ${ }^{4,5,6}$ (D) John Measey ${ }^{2}$ (D)
}

Received: 16 November 2021 / Revised: 15 December 2021 / Accepted: 17 December 2021 / Published online: 5 January 2022

(c) The Author(s), under exclusive licence to Springer-Verlag GmbH Germany, part of Springer Nature 2022

\begin{abstract}
Animals are increasingly challenged to respond to novel or rapidly changing habitats due to urbanization and/or displacement outside their native range by humans. Behavioral differences, such as increased boldness (i.e., propensity for risk-taking), are often observed in animals persisting in novel environments; however, in many cases, it is unclear how these differences arise (e.g., through developmental plasticity or evolution) or when they arise (i.e., at what age or developmental stage). In the Guttural Toad (Sclerophrys gutturalis), adult urban toads from both native and invasive ranges are bolder than conspecifics in natural habitats. Here, we reared Guttural Toad tadpoles in a common garden experiment, and tested for innate differences in boldness across their development and between individuals whose parents and lineage came from rural-native, urban-native, and urban-invasive localities (i.e., origin populations). Tadpoles did not differ in their boldness or in how their boldness changed over ontogeny based on their origin populations. In general, tadpoles typically became less bold as they aged, irrespective of origin population. Our findings indicate that differences in boldness in free-living adult Guttural Toads are not innate in the tadpole stage and we discuss three possible mechanisms driving phenotypic divergence in adult boldness for the focus of future research: habitat-dependent developmental effects on tadpole behavior, decoupled evolution between the tadpole and adult stage, and/or behavioral flexibility, learning, or acclimatization during the adult stage.
\end{abstract}

\section{Significance statement}

To determine if animals can persist in urban areas or become invasive outside their native ranges, it is important to understand how they adapt to life in the city. Our study investigates if differences in boldness that have been found in adult Guttural Toads (Sclerophrys gutturalis) represent heritable differences that can also be found in early life stages by rearing tadpoles from eggs in a common garden experiment. We did not find any differences in boldness among tadpoles from rural-native, urban-native, and urban-invasive origin populations. Our findings suggest that differences in boldness are not innate and/or that boldness is a behavioral trait that is decoupled between the tadpole and the adult stage.

Keywords Amphibian · Behavioral development · Boldness · Evolution · Invasion biology $\cdot$ Urban ecology

Communicated by A. Taylor Baugh

Max Mühlenhaupt

max.muehlenhaupt@sunrisepc.de

1 Department of Biology, Chemistry, Pharmacy, Institute of Biology, Freie Universität Berlin, Königin-Luise-Str. 1-3, 14195 Berlin, Germany

2 Centre for Invasion Biology, Department of Botany and Zoology, Stellenbosch University, Stellenbosch, Western Cape 7600, South Africa

3 College of Agriculture, Engineering \& Science, University of KwaZulu-Natal, 91 Ridge Rd, Pietermaritzburg, Scottsville 3201, South Africa
4 Department of Botany and Zoology, Stellenbosch University, Stellenbosch, Western Cape 7600, South Africa

5 Department of Biology, Dalhousie University, Halifax, Nova Scotia B3H 4R2, Canada

6 Department of Biology, Mount Allison University, Sackville, New Brunswick E4L 1E2, Canada 


\section{Introduction}

Anthropogenic global change poses a host of novel challenges to species worldwide (Grimm et al. 2008; Martin et al. 2010; Pautasso et al. 2010). Two important components of direct or indirect human impact on animals are the urbanization of natural environments and the displacement of animals into non-native ranges (Vitousek et al. 1997; Lambin and Meyfroidt 2011). Interestingly, invasive species distributions are often centered around cities and other anthropogenically modified habitats (Pyšek et al. 2020). This might simply be a result of the more frequent transportation to, and release within, human-modified habitats due to human activity and global inter-connectedness that is inherent to the concept of invasive populations (Hulme 2009; Gaertner et al. 2017; Padayachee et al. 2017). However, recent evidence suggests that the invasiveness of species may be enhanced by prior adaptation to urban environments before they are subsequently released into novel urban ranges, bolstering a population's ability to establish and spread (Hufbauer et al. 2012; Borden and Flory 2021).

Behavioral flexibility is a key mechanism that can enable animals to cope with rapid human-induced environmental changes and can even allow them to thrive in heavily modified habitats like cities (Candolin and Wong 2012; Sol et al. 2013; van Baaren and Candolin 2018). Commonly reported behavioral shifts in response to novel anthropogenically driven conditions, such as urban landscapes or extra-limital introductions, include increases in activity (e.g., Pintor et al. 2008; Pintor and Sih 2009; Philpott et al. 2019), aggression (e.g., Pintor et al. 2008; Evans et al. 2010; Kralj-Fišer and Schneider 2012), boldness (e.g., Atwell et al. 2012; Batabyal et al. 2017; Hewes and Chaves-Campos 2018; Damas-Moreira et al. 2020; Mazza et al. 2020), and tendency to explore (e.g., Thompson et al. 2018; Damas-Moreira et al. 2019; Oliveira et al. 2020), but can vary between taxa and locations. Research on why these behavioral shifts occur indicates that urban-adapted and/or invasive populations can achieve higher growth rates and reproductive output in anthropogenically modified habitats (Peach et al. 2008; Pintor and Sih 2009; Sargent and Lodge 2014; Putman and Tippie 2020; Thawley and Kolbe 2020) by using novel ecological opportunities (e.g., González-Bernal et al. 2012; González-Bernal et al. 2016; Thawley and Kolbe 2020) and outcompeting native species (e.g., Pintor and Sih 2009; Damas-Moreira et al. 2020) while benefitting from reduced predation pressure (Brownscombe and Fox 2013; Eötvös et al. 2018; Westrick et al. 2019) and higher resource availability (Lowry et al. 2013; Tryjanowski et al. 2015; Hradsky et al. 2017); however, many questions remain regarding how these behavioral adaptations arise.
Similar behaviors appear to be beneficial for animals in urbanized or invasive populations (e.g., increased boldness; Atwell et al. 2012; Damas-Moreira et al. 2020; Mazza et al. 2020), yet the mechanism driving these behavioral tendencies is often unclear. Anthropogenically derived phenotypic change may be driven by prior adaptation in the donor habitat (Hufbauer et al. 2012; Borden and Flory 2021), rapid evolution in the novel environment (Whitney and Gabler 2008; Baxter-Gilbert et al. 2019), or realization through developmental plasticity and behavioral flexibility (e.g., Hudson et al. 2017; Hewes and ChavesCampos 2018; Mazza et al. 2020). Furthermore, exactly when trait divergence occurs during ontogeny is largely unknown (e.g., Brodin et al. 2013; Gruber et al. 2017). This question is especially relevant when different ontogenetic stages of an animal exhibit different morphologies and use diverse ecological niches and habitats (Werner 1988; Kelleher et al. 2018). This is more commonplace than one may expect-approximately $80 \%$ of all animals, including insects and amphibians, have these types of complex life cycles (Werner 1988).

We aimed to study evolutionary and ontogenetic divergence of a behavioral trait (i.e., boldness; herein defined as an animal's propensity to exhibit risk-taking behavior) known to differ among populations of an urban-invasive amphibian, the Guttural Toad (Sclerophrys gutturalis). A recent study by Baxter-Gilbert et al. (2021) found that adult toads are bolder in urban habitats than they are in natural areas across native and invasive ranges. This study gives rise to the questions of how (i.e., through evolution or plasticity) and when (i.e., at what age or developmental stage) these differences arise. In a common garden experiment, we raised tadpoles produced from wild adults captured from rural-native, urban-native, and urban-invasive populations (i.e., origin populations). We then quantified the tadpoles' boldness (i.e., latency to leave a hide after a standardized simulated predator attack; Baxter-Gilbert et al. 2021) every 10 days across development to investigate whether differences in boldness between habitat types are genetically fixed, and if so, when do these differences arise ontogenetically. We expected that (1) all tadpoles increase in boldness as they age, due to an increased energy requirement with larger body size, as well as the well-established link between boldness and foraging activity (Wilson and Krause 2012b; Urszán et al. 2015a, b; Kelleher et al. 2018), and (2) urban-invasive tadpoles will be consistently bolder across ontogeny than rural-native tadpoles, with urban-native tadpoles being intermediary, given the reported coupling of boldness across life stages in anurans (Wilson and Krause 2012b; Kelleher et al. 2018). If prediction (2) is supported, then this would also suggest that prior adaptation to invade urban habitats is already present in the tadpole stage of this species (Hufbauer et al. 2012; Borden and Flory 2021). 


\section{Methods}

\section{Study species, sampling sites, and collection of adults}

The Guttural Toad is a large bufonid with a maximum reported snout-vent length (SVL) of $140 \mathrm{~mm}$, that has a wide distribution across much of sub-Saharan Africa (du Preez et al. 2004; Telford et al. 2019). Tadpoles are aquatic and develop over the course of 6 to 10 weeks, after which metamorphosis is complete and they leave the water with a terrestrial body form (du Preez et al. 2004; Channing et al. 2012). This toad is a habitat generalist that is encountered across a range of grassland and forest ecosystems commonly associated with natural wetlands and waterbodies (du Preez et al. 2004; Channing et al. 2012). Yet, it also has a proclivity for synanthropic behavior and can be found in anthropogenic landscapes (e.g., urban/suburban) where they will exploit anthropogenic water bodies such as garden ponds for breeding habitat (du Preez et al. 2004; Vimercati et al. 2017).

The species has successfully established invasive populations on the islands of Mauritius and Réunion and near the city of Cape Town, South Africa (Telford et al. 2019; Baxter-Gilbert et al. 2020). A study by Telford et al. (2019) showed that all invasive populations came from the port city of Durban, South Africa. In the case of the invasive population near Cape Town, eggs and tadpoles are presumed to have been unintentionally introduced via a consignment of aquatic ornamental plants in 1998 (De Villiers 2006; Measey et al. 2017). This urban-invasive Cape Town population has since shown rapid adaptation to the drier climate in the Cape region in the adult stage, altering their behavior, physiology, and reproductive strategy (Vimercati et al. 2018, 2019; Madelaire et al. 2020; Barsotti et al. 2021).

For the purposes of our study, we collected reproductively sized adult toads from November 2019 to February 2020 . We chose two locations to collect toads from natural-native origin populations, hereafter referred to as

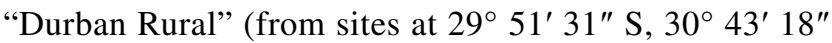
E and $29^{\circ} 28^{\prime} 17^{\prime \prime} \mathrm{S}, 31^{\circ} 13^{\prime} 25^{\prime \prime} \mathrm{E}$ ), which were areas with little human modification that are $20-60 \mathrm{~km}$ from the city of Durban. We also collected toads from two urbannative origin populations, hereafter referred to as "Durban Urban" $\left(29^{\circ} 50^{\prime} 55^{\prime \prime} \mathrm{S}, 31^{\circ} 00^{\prime} 30^{\prime \prime} \mathrm{E}\right.$ and $29^{\circ} 49^{\prime} 08^{\prime \prime} \mathrm{S}$, $30^{\circ} 56^{\prime} 37^{\prime \prime} \mathrm{E}$ ), which were from suburban areas within Durban. Lastly, we collected toads from a single urbaninvasive origin population, hereafter referred to as "Cape Town" (34 01' $\left.29^{\prime \prime} \mathrm{S}, 18^{\circ} 26^{\prime} 03^{\prime \prime} \mathrm{E}\right)$ from the suburb of Constantia, located near Cape Town, where an invasive population of Guttural Toads had become established. The
Durban Rural sites consisted of wetlands with a lake or a series of ponds that showed little anthropogenic modification or signs of low levels of use by humans (e.g., nature reserves and infrequent recreational fishing) and had mostly native plant communities. The Durban Urban sites had artificial water bodies (e.g., ornamental ponds with non-native fish species, ditches, or fountains), frequent anthropogenic structures (e.g., buildings and roads), and high levels of human presence. Similarly, the Cape Town site also had many garden ponds, buildings, roads, and high levels of human presence.

\section{Husbandry of adults and breeding protocols}

After collection, adults were brought to a greenhouse located at the University of KwaZulu-Natal Westville Campus. In this facility, toads were housed by sampling location and sex in large plastic tubs $(1.1 \mathrm{~m}[\mathrm{~L}] \times 1.3 \mathrm{~m}[\mathrm{~W}] \times 0.50 \mathrm{~m}[\mathrm{H}]$; $n=10$ ) filled with $\sim 50 \mathrm{~mm}$ of soil and another $\sim 50 \mathrm{~mm}$ of leaf litter over the soil. Water was provided in plastic bowls ad libitum. We ensured the soil was moist, but not saturated, and fed toads 2-5 adult crickets (Acheta domesticus) every other day.

Toad breeding was carried out from December 2019 to March 2020 using individuals that were available in the greenhouse at the time. Thus, clutches were not deposited synchronously, but rather in clumped batches over the course of this $\sim 3$-month period. Every toad was used only once for breeding. To initiate mating behavior, and subsequent oviposition and fertilization, we used a 1:20 solution of the synthetic gonadotrophin leuroprorelin acetate-"Lucrin" (Lucrin Depot, Abbott) and Ringer's solution. We injected females with $0.666 \mathrm{~mL}$ and males with $0.333 \mathrm{~mL}$ (Hamilton et al. 2005) at 17:00 h. After injection, pairs of males and females were placed inside separate plastic containers $(260 \times 410 \mathrm{~mm})$ filled with $40 \mathrm{~mm}$ of aged tap water and left undisturbed overnight. The next morning at $~ 9: 00 \mathrm{~h}$, we checked the containers for fertilized clutches, removed the adults from the containers, and replaced the water inside these containers with clean, aged tap water to a height of approximately $150 \mathrm{~mm}$. We regularly replaced the water inside these containers and made sure clutches were well aerated. Over the next few days, we followed embryonic development closely. Typically, 1 day after the clutch was laid, most embryos had already hatched (i.e., Gosner stage 20; Gosner 1960). At this point, individuals were assigned a tadpole age of 0 days, allowing us to track age in days for the entirety of our common garden experiment.

\section{Common garden experiment}

We housed tadpoles in large mesocosms (large plastic tubs; $1.1 \mathrm{~m}[\mathrm{~L}] \times 1.3 \mathrm{~m}[\mathrm{~W}] \times 0.5 \mathrm{~m}[\mathrm{H}] ; n=30$ ) filled with 600 
$\mathrm{L}$ of tap water placed halfway below workbenches inside the facility, so that one half of a mesocosm was shaded and the other half received sunlight through the roof panels. We let the water inside the mesocosms age for a week, before adding $\sim 1 \mathrm{~L}$ of water from a standing water tank to each mesocosm to induce zoo- and phyto-plankton establishment. This water tank was located inside the facility (i.e., preventing access from toads and fish) and had a well-established community of aquatic vegetation and algae within it. After another week, we added $50 \mathrm{~g}$ of rabbit chow (Rabbit Pellets, Westerman's Premium) to supply the plankton with additional nutrients (Semlitsch and Boone 2009). At an age of 3 days, we separated 1000 enumerated tadpoles from one clutch (i.e., full siblings) and translocated them to a mesocosm that had been prepared for their arrival approximately 1 month before and contained a well-established and abundant zoo- and phyto-plankton community.

\section{Boldness assay}

At the age of 10 days, and then every subsequent 10 days (Table 1), we haphazardly selected 20 tadpoles from each mesocosm for testing. If we were not able to conduct the assay on the specific day the tadpoles were scheduled for, we conducted the assay on the next possible day (see Table 1). We did not assess Gosner stage (Gosner 1960) of each tadpole as this would have required additional handling. Generally, developmental stages of individual tadpoles varied greatly within a clutch (e.g., between Gosner stages 25 and 30 for younger clutches and Gosner stages 30 and 41 for older clutches; Gosner 1960). However, for older tadpoles, we ensured that only tadpoles that had not

Table 1 The number of tadpoles whose boldness was assayed in our study, separated by age and origin population. Numbers in parentheses denote the total number of clutches the tadpoles belonged to. For Durban Rural, 3 and 7 clutches were produced from toads collected in sampling location 1 or 2, respectively, and for Durban Urban, 6 and 6 clutches from sampling location 1 or 2 , respectively (see "Methods"). Please note that due to the staggered breeding of adults over a period of 3 months, as well as the onset of COVID-19 pandemic restrictions in South Africa in March 2020, sample sizes are lower for higher ages as we were not able to continue the data collection after this time

\begin{tabular}{llll}
\hline Age & Durban Rural & Durban Urban & Cape Town \\
\hline 10 & $180(9)$ & $220(11)$ & $160(8)$ \\
12 & $20(1)$ & $20(1)$ & - \\
20 & $200(10)$ & $179(9)$ & $159(8)$ \\
30 & $200(10)$ & $180(9)$ & $80(4)$ \\
40 & $119(6)$ & $179(9)$ & $80(4)$ \\
41 & $40(2)$ & - & - \\
50 & $60(3)$ & $180(9)$ & $60(3)$ \\
60 & $59(3)$ & $100(5)$ & $40(2)$ \\
$\Sigma$ & $\mathbf{8 7 8}$ & $\mathbf{1 0 5 8}$ & $\mathbf{5 7 9}$ \\
\hline
\end{tabular}

developed past Gosner stage 41 (Gosner 1960) were used, as strong morphological and physiological changes might affect behavior in subsequent developmental stages (Dodd and Dodd 1976). We used $190[\mathrm{~L}] \times 300[\mathrm{~W}] \mathrm{mm}$ plastic containers filled with $20 \mathrm{~mm}$ of aged tap water as boldness arenas. Above the boldness arenas, we installed digital video cameras (recording at a frame rate of $25 \mathrm{fps}$ and a resolution of $101.38 \mathrm{kP}$ ), that allowed us to remotely record the tadpole behavior (i.e., without a researcher present). Before the start of each boldness assay, tadpoles were tested for swimming performance (Mühlenhaupt et al. 2021) and were introduced to the boldness arenas immediately afterwards. Before starting the simulated predator attack, we documented the water temperature in the boldness arenas using a digital thermometer (Control Company, product code: $4052 ; \pm 0.1{ }^{\circ} \mathrm{C}$ ). Using the tip of a red silicon spatula, a single researcher (MM) chased the tadpoles for $10 \mathrm{~s}$ before placing a circular hide (i.e., a white opaque plastic cup with a diameter of $116 \mathrm{~mm}$ with a $50[\mathrm{~W}] \times 30[\mathrm{H}] \mathrm{mm}$ exit hole cut into the side) over them. The hide, while it was surrounding the tadpole, was then centered within the arena and the exit hole aligned to be visible by the camera. For the next $20 \mathrm{~min}$, we recorded tadpole behavior. From these video recordings, we scored whether tadpoles left the hide during the duration of recording (binary variable) and documented the time (s) it took the tadpoles to leave the hide (i.e., latency to leave the hide). For the latter behavior, we considered a tadpole had left the hide when it had passed through the exit hole with the vent exposed and the tip of the snout facing perpendicular to the hide. Video scoring was carried out by one observer (MM) who was blind to the origin populations of tadpoles. Tadpoles that did not leave the hide were assigned the maximum assay time (1200 s; as per Riley et al. 2017; Damas-Moreira et al. 2019; Baxter-Gilbert et al. 2021). This protocol closely followed the boldness assay used by Baxter-Gilbert et al. (2021). We measured the same variables and began each boldness assay with a standardized "mock predation" event (i.e., chasing the tadpoles for $10 \mathrm{~s}$ with a rubber spatula) to ensure comparability of our results with those of Baxter-Gilbert et al. (2021). Furthermore, we ensured that boldness, as quantified here, was not conflated with general activity by simulating a risky situation through the "mock predation" event at the beginning of each assay (see Réale et al. 2007; Kelleher et al. 2018).

After the boldness assay, we returned the tadpoles to their respective mesocosms. Thus, we cannot rule out the possibility that any individual tadpole was also sampled for a boldness assay at a different age, and we acknowledge that recurrent behavioral testing can influence tadpole behavior in later trials (Urszán et al. 2015a). However, given the high initial number of tadpoles per mesocosm $(n=1000)$, there is 
a low likelihood that many tadpoles were repeatedly used for testing and thus, we conducted statistical analysis assuming non-repeated measures.

\section{Statistical analysis}

All statistical analyses were carried out using R (Version 4.0.1; R Core Team 2020). Before analyzing our data, we explored the data set following Zuur et al. (2010) and did not find any unexplainable outliers. We verified the assumptions of normality and homoscedasticity of residuals for all models prior to interpretation and present data as predicted means \pm standard error (SE) in the text. The significance level $(\alpha)$ was set at 0.05 for all models. The water temperature during the boldness trials and the age of tadpoles were significantly correlated (confirmed by using the "Im" and "Anova" function in the $\mathrm{R}$ "stats" package; $\mathrm{R}$ Core Team 2020: $\left.F_{1,2493}=11.12, p<0.01\right)$. Therefore, we decided to exclude temperature from our models because these two factors are confounded. However, due to our staggered breeding protocol (see "Husbandry of adults and breeding protocols"), younger and older tadpoles were tested at the end of the experiment, so seasonal variation in temperature likely did not affect our results strongly.

First, we investigated the proportion of tadpoles that did not leave the hide during the 20-min trial. The variability in this behavioral trait was very low (overall less than $1 \%$ of tadpoles did not exit the hide; Table 2). Thus, we present a summary of this behavioral trait, but it was not analyzed statistically. Instead, we used the tadpole's latency to leave the hide (s) as our boldness metric and, before analyses, we rank-transformed these values because they were strongly positively skewed (Riley et al. 2017; Damas-Moreira et al. 2019). We used a linear mixed effect model (LMM; using

Table 2 A summary of the number of tadpoles that did not leave the hide during the 20-min boldness assays separated by age and origin population. Numbers in parentheses denote the specific percentage $(\%)$ of tadpoles that did not leave the hide as calculated from the number of tadpoles that did not leave the hide divided by the total number of tadpoles assayed at that age and specific origin population (see Table 1)

\begin{tabular}{llll}
\hline Age & Durban Rural & Durban Urban & Cape Town \\
\hline 10 & 0 & $2(1 \%)$ & 0 \\
12 & 0 & 0 & 0 \\
20 & 0 & 0 & $1(0.63 \%)$ \\
30 & $3(1.5 \%)$ & $2(1 \%)$ & $1(1.25 \%)$ \\
40 & $2(1.68 \%)$ & $1(0.56 \%)$ & $1(1.25 \%)$ \\
41 & 0 & 0 & 0 \\
50 & 0 & $3(1.67 \%)$ & $1(1.67 \%)$ \\
60 & $2(3.39 \%)$ & 0 & $1(2.5 \%)$ \\
$\Sigma$ & $\mathbf{7 ( 0 . 8 \% )}$ & $\mathbf{8 ( 0 . 7 6 \% )}$ & $\mathbf{5 ( 0 . 8 6 \% )}$ \\
\hline
\end{tabular}

the "Imer" function in the R package "lme4"; Bates et al. 2015) with our boldness metric as the response variable that included the fixed effects of tadpole origin population (categorical: Cape Town, Durban Rural, Durban Urban), age (continuous), and initially included the interaction between origin population and age. This LMM also included a random intercept and slope of mesocosm number to control for dependency in our data due to relatedness and shared housing for individuals from the same tub, and a random intercept of parentage location to control for dependency in our data due to similarities between specific study sites where the parents were collected. Post hoc, we tested for an interaction effect using "emtrends" in the R package "emmeans" (Lenth et al. 2018) and did not find any significant effects (all $p_{\text {corr }}>0.16$; $p$-values were corrected using a "Tukey" adjustment). Thus, we removed the interaction term and reran the LMM to allow interpretation of main effects.

We also ran a separate LMM investigating differences in the boldness of tadpoles that were 40/41 days old among the different origin populations. This LMM had our boldness metric as the response variable, included tadpole origin population (categorical: Cape Town, Durban Rural, Durban Urban) as a fixed factor, and a random intercept of mesocosm number and parentage site. We chose this age because tadpoles had sufficient time to develop and possibly diverge in boldness, sample size was still reasonably high (Table 1), and, around this age, Guttural Toad tadpoles are known to begin emergence as toadlets (du Preez et al. 2004; Channing et al. 2012). Furthermore, our previous work has indicated that tadpoles from different origin populations show differences in developmental rate (Mühlenhaupt et al. 2021). Thus, with higher age (e.g., 50 or 60 days), our results might be biased towards slow-developing Durban Urban tadpoles because fast-developing Durban Urban tadpoles might have already exceeded Gosner stage 41 (Gosner 1960).

Following analysis of both LMMs, we conducted post hoc multiple comparisons between tadpole origin populations using the R package "emmeans" and $p$-values generated for these comparisons were "Tukey" adjustment-corrected using a Monte Carlo method to produce "exact" Tukey corrections (Lenth et al. 2018).

\section{Results}

The proportion of tadpoles that did not leave the hide during our boldness assay was very low, with less than $1 \%$ of tadpoles remaining in the hide during the trials (Table 2). Tadpoles became less bold (i.e., shyer) as they aged, but boldness did not differ between origin populations (Table 3 , Fig. 1). Similarly, at the age of 40/41 days, tadpole boldness did not differ among origin populations (Table 4, Fig. 2). 
Table 3 (a) Output from the linear mixed effects model examining differences in boldness scores (i.e., rank-transformed latency to leave the hide) over the first 60 days of development in Guttural Toad tadpoles. The interaction between tadpole origin population and age was not significant, so it was removed, and the model was re-run. Model estimates $(\beta)$ of fixed effects are presented with their corresponding standard errors (SE), Satterthwaite-approximated degrees of freedom (df), and $t$-values. Variance estimates $\left(\sigma^{2}\right)$ are supplied for residuals and random effects, and all significant values $(p<0.05)$ are bolded. Levels for tadpole origin population are given in parentheses following the variable name. (b) We also present post hoc multiple comparisons of boldness between all tadpole origin populations and, in this case, $p$-values $\left(p_{\text {corr }}\right)$ were corrected using a "Tukey" adjustment (Lenth et al. 2018)

\begin{tabular}{|c|c|c|c|c|c|}
\hline \multicolumn{6}{|l|}{ (a) Model output } \\
\hline Fixed effects & $\beta$ & SE & df & $t$ & $p$ \\
\hline Intercept (Cape Town) & -0.26 & 0.07 & 158.35 & -3.71 & $<0.01$ \\
\hline $\begin{array}{l}\text { Tadpole origin (Durban } \\
\text { Rural) }\end{array}$ & 0.00 & 0.08 & 84.94 & -0.03 & 0.97 \\
\hline $\begin{array}{l}\text { Tadpole origin (Durban } \\
\text { Urban) }\end{array}$ & 0.08 & 0.08 & 108.05 & 0.94 & 0.35 \\
\hline Age & 0.01 & $\mathbf{0 . 0 0}$ & 33.01 & 4.01 & $<0.01$ \\
\hline Random effects & $\sigma^{2}$ & & & & \\
\hline Mesocosm ID & 0.00 & & & & \\
\hline Parentage site & 0.00 & & & & \\
\hline Residuals & 0.94 & & & & \\
\hline \multicolumn{6}{|c|}{$\begin{array}{l}\text { (b) Post hoc multiple comparisons between tadpole origin popula- } \\
\text { tions }\end{array}$} \\
\hline & $\beta$ & SE & df & $z$ & $p_{\text {corr }}$ \\
\hline Cape Town - Durban Rural & 0.00 & 0.09 & 1.03 & 0.03 & 0.99 \\
\hline Cape Town - Durban Urban & -0.08 & 0.08 & 1.02 & -0.92 & 0.63 \\
\hline $\begin{array}{l}\text { Durban Rural - Durban } \\
\text { Urban }\end{array}$ & -0.08 & 0.08 & 1.54 & -0.96 & 0.60 \\
\hline
\end{tabular}

\section{Discussion}

Contrary to our predictions, tadpole boldness did not differ among rural-native, urban-native, and urban-invasive origin populations, and decreased with tadpole age in our common garden experiment. Given the clear divergence in boldness among natural and urban adult Guttural Toads (Baxter-Gilbert et al. 2021), this study gives valuable insight in how urban-derived boldness in Guttural Toads may or may not arise. Notably, this would suggest that the increased boldness observed in adult urban toads is either a result of experience or plasticity at either the tadpole or adult stage (i.e., requiring exposure to actual urban/rural ecosystems), or if it is heritable and fixed, then the phenotype is not expressed until after metamorphosis. Within the scope of this study, since bolder phenotypes are not uniquely arising in the larval stage of urbanized Guttural Toads, we would assert that prior-adaptation is not enhancing the species' invasion success (Hufbauer et al. 2012; Borden and Flory 2021), with respect to tadpole boldness. In the context of the recent

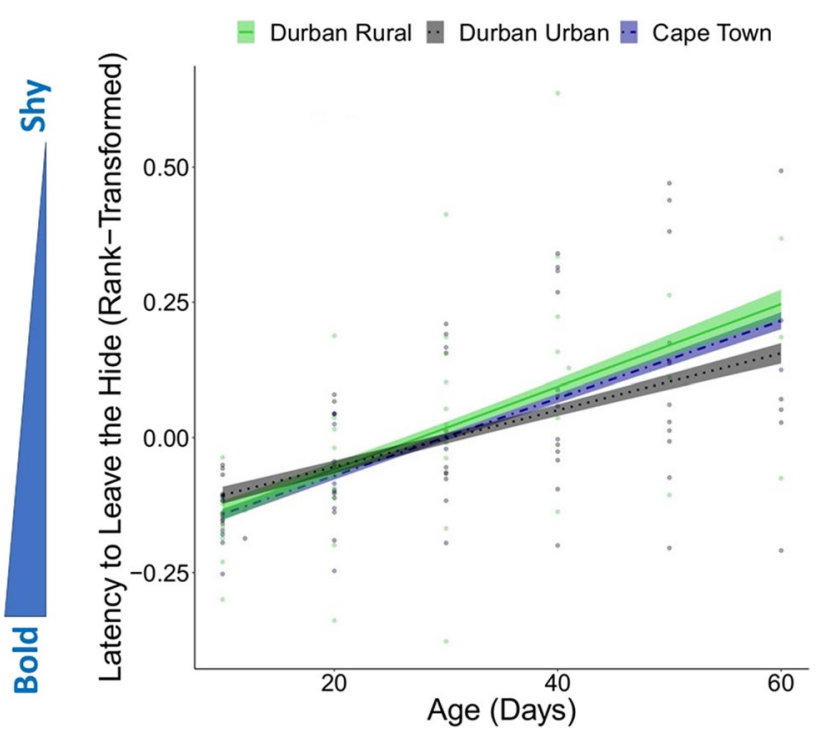

Fig. 1 Guttural Toad tadpole boldness (i.e., rank-transformed latency to leave the hide after a standardized simulated predation attempt) as they aged for each origin population as predicted from our linear mixed effect model (Durban Rural $=$ green with solid line, Durban Urban = black with dotted line, Cape Town = blue with dashed line). Predicted data points are shown with corresponding linear regression lines and 95\% confidence intervals. The blue triangle on the left corresponds with the directionality of the trait (i.e., low values correspond with bold tadpoles and vice versa)

Table 4 (a) Output from the linear mixed effects model examining differences in Guttural Toad tadpole boldness (i.e., rank-transformed latency to leave the hide) at the age of $40 / 41$ days. For fixed effects, model estimates $(\beta)$ are presented with their corresponding standard errors (SE), Satterthwaite-approximated degrees of freedom (df), and $t$-values. For residuals and random effects, variance estimates $\left(\sigma^{2}\right)$ are supplied. Levels for tadpole origin population are given in parentheses following the variable name. (b) We also present post hoc multiple comparisons of boldness between all tadpole origin populations, and, in this case, $p$-values $\left(p_{\text {corr }}\right)$ were corrected using a "Tukey" adjustment (Lenth et al. 2018)

(a) Model output

Variable names

$\begin{array}{llllll}\text { Fixed effects } & \beta & \text { SE } & \text { df } & t & p \\ \text { Intercept (Cape Town) } & 0.04 & 0.22 & 1.88 & 0.15 & 0.90 \\ \text { Tadpole origin (Durban Rural) } & 0.09 & 0.27 & 1.88 & 0.34 & 0.77 \\ \text { Tadpole origin (Durban Urban) } & -0.13 & 0.26 & 1.82 & -0.50 & 0.68 \\ \text { Random effects } & \sigma^{2} & & & & \\ \text { Mesocosm ID } & 0.04 & & & & \\ \text { Parentage Site } & 0.03 & & & & \\ \text { Residuals } & 1.00 & & & & \end{array}$

(b) Post hoc multiple comparisons between tadpole origin populations

Cape Town - Durban Rural

$\beta \quad$ SE df $z \quad p_{\text {corr }}$

Cape Town - Durban Urban

$\begin{array}{lllll}-0.09 & 0.27 & 1.94 & -0.33 & 0.94\end{array}$

Durban Rural - Durban Urban

$\begin{array}{llllll}0.13 & 0.27 & 1.87 & 0.49 & 0.88\end{array}$

$\begin{array}{llllll}0.22 & 0.22 & 1.85 & 1.00 & 0.58\end{array}$ 


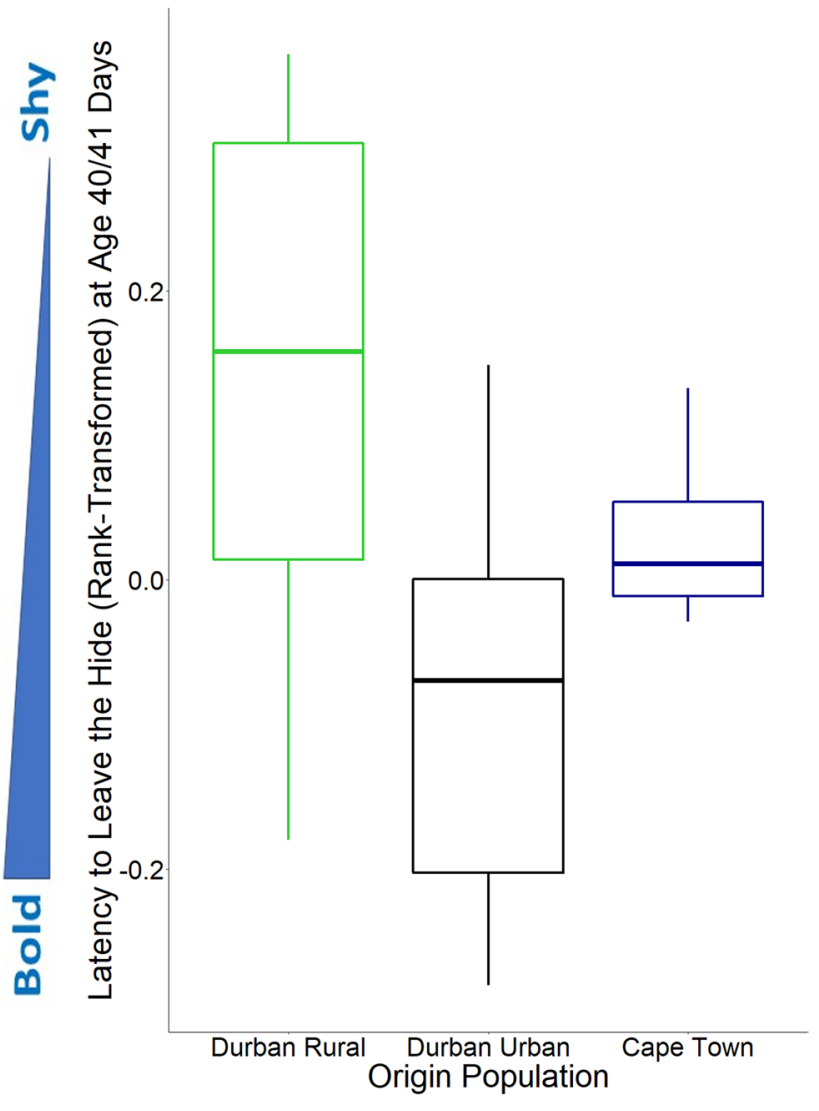

Fig. 2 Guttural Toad tadpole boldness (i.e., rank-transformed latency to leave the hide after a standardized simulated predation attempt) at the age of 40/41 days. Depicted are boxplots of predicted data from a linear mixed effect model testing for differences between Durban Rural (green), Durban Urban (black), and Cape Town (blue) tadpoles. The thick horizontal line in the boxplots corresponds with the predicted median, the boxes represent the second and third quartile ranges, and the whiskers encompass the minimum and maximum of the data. We did not find any significant differences in boldness among tadpoles from different origin populations (Table 2). The blue triangle on the left depicts the directionality of the trait (i.e., low values correspond with bold tadpoles and vice versa)

surge in studies examining rapid evolution in urban and invasive populations, our study results demonstrate a break with many significant findings on larval stages, suggesting substantial gaps in our understanding of the mechanisms and timing by which these phenotypic differences arise, and support the recommendation for more robust methodologies (see Lambert et al. 2020).

Our common garden experimental design gives us the ability to demonstrate strong evidence that Guttural Toad tadpoles are not expressing heritable or innate differences in their boldness between populations (Lambert et al. 2020). These findings are contrary to previous research which showed heritable differences in tadpole boldness between mainland and island populations of Common Frogs (Rana temporaria) that were carried over to the adult stage
(Brodin et al. 2013). In Common Frogs, the bolder phenotype of island populations was presumed to be the result of a disperser-dependent founder effect through bolder, more exploratory adults colonizing the new islands that rose above sea level approximately 350-800 years ago (Brodin et al. 2013), which is similar to the increased levels of boldness seen in invasive range-front (i.e., expanding) adult Cane Toads (Rhinella marina) in Australia after less than 100 years (Gruber et al. 2017). In the context of Guttural Toads, however, it is more likely that a population around the area of Durban already existed before the city was founded and became urbanized during the city's founding and growth (Baxter-Gilbert et al. 2021). Furthermore, the Cape Town population of Guttural Toads was likely established through tadpoles or eggs, both of which are non-dispersive life stages (De Villiers 2006; Measey et al. 2017). Thus, a disperserdependent founder effect is unlikely in the urban and urbaninvasive populations of the Guttural Toad, emphasizing the context-dependent nature of behavioral divergence between populations. Similarly, a previous study showed that urbannative and urban-invasive tadpoles do not differ in swimming performance and underlying morphological traits compared to rural-native tadpoles in the Guttural Toad (Mühlenhaupt et al. 2021), suggesting that predation pressure might not be reduced in urban and/or invasive tadpole habitats.

Although our findings suggest that urbanized or invasive Guttural Toad tadpoles are not exhibiting heritable increases in boldness, the drivers of the observed differences in adult boldness between urban and rural adults (Baxter-Gilbert et al. 2021) remain unknown. One possibility is that phenotypic differences could be the result of developmental effects experienced during the tadpole stage, which may be habitat-dependent for their expression in tadpoles and are carried over and expressed during post-metamorphic stages. Tadpoles are well known to show high levels of plasticity in many traits as a response to different ecological factors (Richardson 2001; Relyea 2002; Van Buskirk 2002; Relyea 2004) and differences in stress response between urban, agricultural, and rural Common Toad (Bufo bufo) tadpoles are seen to be a result of phenotypic plasticity (Bókony et al. 2021). Furthermore, more active, explorative, and bolder phenotypes in Lake Frog (Pelophylax ridibundus) tadpoles are seen to be carried over to the adult stage (Wilson and Krause 2012b) and if these traits arise through plasticity, then variable environments would be required to trigger their expression. As such, due to the controlled nature of our common garden experimental design, if the bolder phenotypes are a result of plasticity, then it is not surprising that we were unable to detect them in this study. A reciprocal transplant experiment might help to elucidate what role phenotypic plasticity of boldness and the evolution of plasticity in this trait play in shaping the bolder urban phenotype of adult toads (Baxter-Gilbert et al. 2021). For example, plasticity in 
boldness might have evolved only in urban populations, and then may only be observable if the correct stimuli are present during development to trigger a shift in boldness (e.g., Iraeta et al. 2006; Kaiser et al. 2019).

Conversely, differential expression of boldness between adults but not tadpoles might be the result of decoupled evolution between life stages in Guttural Toads (Collet and Fellous 2019). Decoupling of traits has recently been shown in the invasive African Clawed Frog (Xenopus laevis; Kruger et al. 2021). Adults from the periphery of the invasive range in France show a distinct dispersal-mediating phenotype compared to adults from the core (Louppe et al. 2018; Padilla et al. 2019). However, when reared from the egg to the post-metamorphic frog, those differences were not apparent, indicating that differences in adult traits emerge well after metamorphosis (Kruger et al. 2021). Similarly, in a previous study, we presented data indicating that adult Guttural Toads are larger in urban areas but did not find differences in growth rates of tadpoles when raised in a common garden environment (Mühlenhaupt et al. 2021). The amphibian larval stage is typically more sedentary and adapted for foraging and growth, whereas the adult stage is more mobile and adapted for dispersal and reproduction (Wilson and Krause 2012a). Combined with the far-reaching changes in the environment from the aquatic to the terrestrial habitat (Dodd and Dodd 1976), differential selective forces are likely acting on both stages and decoupling of traits across metamorphosis could enhance phenotypic match in the environment experienced by the specific ontogenetic stage (Wilbur 1980; Collet and Fellous 2019; Goedert and Calsbeek 2019). Therefore, if selection has favored increased boldness in urbanized and/or invasive Guttural Toad populations, then the expression of this trait may well be evolutionarily decoupled between the sedentary tadpole life stage and the active, dispersing, and mate-searching adult life stage.

Beyond an evolutionary mechanism (e.g., local adaptation), the presence of bolder urbanized adult Guttural Toads (Baxter-Gilbert et al. 2021), but the absence of such a trait in tadpoles, may be a result of circumstance, due to behavioral flexibility, learning, and/or acclimatization (e.g., Levey et al. 2009; Wright et al. 2010; Couchoux and Cresswell 2012; Vincze et al. 2016; Evans et al. 2019). For example, several phenotypic traits of adult invasive Cane Toads are strongly influenced by prior experience and developmental environment, such as thermal acclimation (McCann et al. 2014) or antipredator response (Hudson et al. 2017). Novel environments, such as cities or the extra-limital ranges of introduced populations, often require animals to phenotypically respond rapidly to novel or stressful ecological conditions (Grimm et al. 2008). Behavioral flexibility and learning represent some of the quickest mechanisms to adaptively match novel selective regimes (Ghalambor et al. 2007; Lande 2009; Fox et al. 2019). Such scenarios can be seen with Northern
Mockingbirds (Mimus polyglottos), which are capable of rapidly learning and identifying individual humans and adjusting their flight distance based on their prior experience with a specific person (Levey et al. 2009), or experience-driven decreases in risk aversion by Burrowing Owls (Athene cunicularia) towards humans (Cavalli et al. 2018). Therefore, it follows that Guttural Toads in urban habitats could have their behavioral traits incrementally shaped through differential experiences, rather than evolutionary mechanisms, resulting in the expression of a bolder adult phenotype in these populations.

Our finding that tadpoles became less bold with increasing age provides clear evidence that boldness levels can change across ontogeny, even within a given life stage, which provides important insights for future research looking to disentangle where the divergence in adult boldness between urban and rural populations occurs (Baxter-Gilbert et al. 2021). This finding was contrary to our predictions because, as we expected that older and larger tadpoles would spend more time foraging, and as there often is a correlation between foraging activity and boldness, we expected our tadpoles to also be bolder as they aged (Wilson and Krause 2012b; Urszán et al. 2015a, b; Kelleher et al. 2018). However, our results aligned with previous research on Common Toad tadpoles, similarly reared in a common garden environment, which were shown to decrease their activity levels (which can correlate with boldness; Kelleher et al. 2018) across larval development (Kurali et al. 2018). Thus, it is likely that tadpoles early in development (after the consumption of the yolk sac; Gosner 1960) show increased foraging activity and boldness to enhance resource acquisition, which then lessen over time due to consequent growth and energy storage (Ramamonjisoa et al. 2019; Davenport et al. 2020). This change in behavioral traits across ontogeny, potentially related to energetics, will also play an important role in interpreting future research on how traits, like boldness, change between life stages and how this may or may not relate to adaptive behavioral shifts associated with urbanization or biological invasions.

Overall, we showed that there is no innate difference in boldness among Guttural Toad tadpoles from rural-native, urban-native, and urban-invasive ranges, despite the welldocumented divergence of boldness in adults (Baxter-Gilbert et al. 2021). Our study highlights the importance of studying the ontogenetic and environmental context of behavioral shifts in novel environments. We encourage researchers, interested in rapid evolution in urban and novel environments, to carefully choose experimental approaches that identify the underlying mechanisms driving population divergence (see Lambert et al. 2020). Although this study was able to provide evidence against one potential driver of human-induced behavioral change (i.e., fixed, heritable traits that persist across life stages) within this study system, there 
remains a number of alternative mechanisms and means from which phenotypes can arise that will require future research.

Acknowledgements We would like to thank NCC Environmental Services (Western Cape), Durban Botanic Gardens, University of KwaZulu-Natal Westville Campus, and Shongweni Dam and Nature Reserve for providing us with toads or access to their facilities for toad collection. Thanks to both N.S. Dludla for assistance during the experiment and P. Kowalski for assistance during fieldwork. We would like to thank J. Jeschke and the members of the MeaseyLab at Stellenbosch University for providing helpful comments and discussions that helped shape this research and manuscript. An anonymous reviewer, B. Carlson, and T. C. M. Bakker helped improve the quality of this manuscript.

Funding This work was funded by the DSI-NRF Centre of Excellence for Invasion Biology (JBG \& JM) and the Centre for Collaborations in Africa at Stellenbosch University (JBG). Also, during this work, JLR's postdoctoral salary was supplied by the Claude Leon Foundation and Natural Sciences and Engineering Research Council of Canada.

Data availability The datasets and $\mathrm{R}$ code for this study are available from Open Source Framework (OSF) and can be found at https://doi. org/10.17605/osf.io/9pten.

\section{Declarations}

Ethical approval Ethical approvals for toad captures and the experimental protocols followed animal ethics guidelines set out and approved by the Stellenbosch University Research Ethics Committee (ACU-2019-13154) and the University of KwaZulu-Natal Animal Research Ethics Committee (AREC/009/020). Field collections in the native range were undertaken under an Ezemvelo KZN Wildlife Ordinary Permit (OP 4072/2019) and a Cape Nature Permit to Export and Transport Protected Wild Animals (CN13-59-12357) for toads from the invasive range.

Conflict of interest The authors declare no competing interests.

\section{References}

Atwell JW, Cardoso GC, Whittaker DJ, Campbell-Nelson S, Robertson KW, Ketterson ED (2012) Boldness behavior and stress physiology in a novel urban environment suggest rapid correlated evolutionary adaptation. Behav Ecol 23:960-969. https://doi.org/10. 1093/beheco/ars059

Barsotti AMG, Madelaire CB, Wagener C, Titon B Jr, Measey J, Gomes FR (2021) Challenges of a novel range: water balance, stress, and immunity in an invasive toad. Comp Biochem Physiol A 253:110870. https://doi.org/10.1016/j.cbpa.2020.110870

Batabyal A, Balakrishna S, Thaker M (2017) A multivariate approach to understanding shifts in escape strategies of urban lizards. Behav Ecol Sociobiol 71:83. https://doi.org/10.1007/ s00265-017-2307-3

Bates D, Mächler M, Bolker B, Walker S (2015) Fitting linear mixedeffects models using lme4. J Stat Softw 67:1-48. https://doi.org/ 10.18637/jss.v067.i01

Baxter-Gilbert J, Riley JL, Measey J (2021) Fortune favors the bold toad: urban-derived behavioral traits may provide advantages for invasive amphibian populations. Behav Ecol Sociobiol 75:130. https://doi.org/10.1007/s00265-021-03061-w
Baxter-Gilbert J, Riley JL, Wagener C, Mohanty NP, Measey J (2020) Shrinking before our isles: the rapid expression of insular dwarfism in two invasive populations of guttural toad (Sclerophrys gutturalis). Biol Lett 16:20200651. https://doi. org/10.1098/rsbl.2020.0651

Baxter-Gilbert J, Riley JL, Whiting MJ (2019) Bold New World: urbanization promotes an innate behavioral trait in a lizard. Behav Ecol Sociobiol 73:105. https://doi.org/10.1007/ s00265-019-2713-9

Bókony V, Ujhegyi N, Hamow KÁ, Bosch J, Thumsová B, Vörös J, Aspbury AS, Gabor CR (2021) Stressed tadpoles mount more efficient glucocorticoid negative feedback in anthropogenic habitats due to phenotypic plasticity. Sci Total Environ 753:141896. https://doi.org/10.1016/j.scitotenv.2020.141896

Borden JB, Flory S (2021) Urban evolution of invasive species. Front Ecol Environ 19:184-191. https://doi.org/10.1002/fee.2295

Brodin T, Lind MI, Wiberg MK, Johansson F (2013) Personality trait differences between mainland and island populations in the common frog (Rana temporaria). Behav Ecol Sociobiol 67:135-143. https://doi.org/10.1007/s00265-012-1433-1

Brownscombe JW, Fox MG (2013) Living at the edge of the front; reduced predation risk to invasive round goby in a Great Lakes tributary. Hydrobiologia 707:199-208. https://doi.org/10.1007/ s10750-012-1427-z

Candolin U, Wong BB (2012) Behavioural responses to a changing world: mechanisms and consequences. Oxford University Press, Oxford. https://doi.org/10.1093/acprof:osob1/9780199602568. 001.0001

Cavalli M, Baladrón AV, Isacch JP, Biondi LM, Bó MS (2018) The role of habituation in the adjustment to urban life: an experimental approach with burrowing owls. Behav Process 157:250-255. https://doi.org/10.1016/j.beproc.2018.10.011

Channing A, Rödel M-O, Channing J (2012) Tadpoles of Africa: the biology and identification of all known tadpoles in Sub-Saharan Africa. Chimaira, Frankfurt am Main

Collet J, Fellous S (2019) Do traits separated by metamorphosis evolve independently? Concepts and methods. Proc R Soc B 286:20190445. https://doi.org/10.1098/rspb.2019.0445

Couchoux C, Cresswell W (2012) Personality constraints versus flexible antipredation behaviors: how important is boldness in risk management of redshanks (Tringa totanus) foraging in a natural system? Behav Ecol 23:290-301. https://doi.org/10.1093/beheco/ $\operatorname{arr} 185$

Damas-Moreira I, Riley JL, Carretero MA, Harris DJ, Whiting MJ (2020) Getting ahead: exploitative competition by an invasive lizard. Behav Ecol Sociobiol 74:117. https://doi.org/10.1007/ s00265-020-02893-2

Damas-Moreira I, Riley JL, Harris DJ, Whiting MJ (2019) Can behaviour explain invasion success? A comparison between sympatric invasive and native lizards. Anim Behav 151:195-202. https:// doi.org/10.1016/j.anbehav.2019.03.008

Davenport JM, King AB, Riley AW, Hampson ME, Constantinides P (2020) The non-consumptive effects of predators and personality on prey growth and mortality. Ethology 126:363-371. https://doi. org/10.1111/eth.12981

De Villiers A (2006) Amphibia: Anura: Bufonidae Bufo gutturalis Power, 1927 guttural toad introduced population. Afr Herpetol News 40:28

Dodd M, Dodd J (1976) The biology of metamorphosis. In: Lofts B (ed) Physiology of the Amphibia, vol 3. Academic Press, New York, pp 467-599 10.1016

du Preez LH, Weldon C, Cunningham M, Turner A (2004) Bufo gutturalis Power, 1927. In: Minter LR, Burger M, Harrison JA, Braack HH, Bishop PJ, Kloepfer D (eds) Atlas and red data book of the frogs of South Africa. Lesotho and Swaziland. Smithsonian Institution and Avian Demographic Unit, Washington DC, pp 67-69 
Eötvös CB, Magura T, Lövei GL (2018) A meta-analysis indicates reduced predation pressure with increasing urbanization. Landsc Urban Plan 180:54-59. https://doi.org/10.1016/j.landurbplan. 2018.08.010

Evans J, Boudreau K, Hyman J (2010) Behavioural syndromes in urban and rural populations of song sparrows. Ethology 116:588-595. https://doi.org/10.1111/j.1439-0310.2010.01771.x

Evans MJ, Hawley JE, Rego PW, Rittenhouse TAG (2019) Hourly movement decisions indicate how a large carnivore inhabits developed landscapes. Oecologia 190:11-23. https://doi.org/10. 1007/s00442-018-4307-z

Fox RJ, Donelson JM, Schunter C, Ravasi T, Gaitán-Espitia JD (2019) Beyond buying time: the role of plasticity in phenotypic adaptation to rapid environmental change. Phil Trans R Soc B 374:20180174. https://doi.org/10.1098/rstb.2018.0174

Gaertner M, Wilson JR, Cadotte MW, MacIvor JS, Zenni RD, Richardson DM (2017) Non-native species in urban environments: patterns, processes, impacts and challenges. Biol Invasions 19:3461-3469. https://doi.org/10.1007/s10530-017-1598-7

Ghalambor CK, McKay JK, Carroll SP, Reznick DN (2007) Adaptive versus non-adaptive phenotypic plasticity and the potential for contemporary adaptation in new environments. Funct Ecol 21:394-407. https://doi.org/10.1111/j.1365-2435.2007.01283.x

Goedert D, Calsbeek R (2019) Experimental evidence that metamorphosis alleviates genomic conflict. Am Nat 194:356-366. https:// doi.org/10.1086/704183

González-Bernal E, Greenlees M, Brown GP, Shine R (2012) Cane toads on cowpats: commercial livestock production facilitates toad invasion in tropical Australia. PLoS One 7:e49351. https:// doi.org/10.1371/journal.pone.0049351

González-Bernal E, Greenlees M, Brown GP, Shine R (2016) Toads in the backyard: why do invasive cane toads (Rhinella marina) prefer buildings to bushland? Popul Ecol 58:293-302. https://doi. org/10.1007/s10144-016-0539-0

Gosner KL (1960) A simplified table for staging anuran embryos and larvae with notes on identification. Herpetologica 16:183-190. https://doi.org/10.2307/3890061

Grimm NB, Faeth SH, Golubiewski NE, Redman CL, Wu J, Bai X, Briggs JM (2008) Global change and the ecology of cities. Science 319:756-760. https://doi.org/10.1126/science.1150195

Gruber J, Brown G, Whiting MJ, Shine R (2017) Is the behavioural divergence between range-core and range-edge populations of cane toads (Rhinella marina) due to evolutionary change or developmental plasticity? R Soc Open Sci 4:170789. https://doi. org/10.1098/rsos.170789

Hamilton NH, Halliday DC, Tarmo S, Bray J, Venables D, Robinson T (2005) Captive care and breeding of marine toads, Bufo marinus. J Herpetol Med Surg 15:21-27. https://doi.org/10.5818/15299651.15.4.21

Hewes ME, Chaves-Campos J (2018) Boldness related to size in the hermit crab Coenobita compressus at undisturbed, but not disturbed beach. Ethology 124:570-578. https://doi.org/10.1111/ eth.12766

Hradsky BA, Robley A, Alexander R, Ritchie EG, York A, Di Stefano J (2017) Human-modified habitats facilitate forest-dwelling populations of an invasive predator, Vulpes vulpes. Sci Rep 7:12291. https://doi.org/10.1038/s41598-017-12464-7

Hudson CM, Brown GP, Shine R (2017) Evolutionary shifts in antipredator responses of invasive cane toads (Rhinella marina). Behav Ecol Sociobiol 71:134. https://doi.org/10.1007/ s00265-017-2367-4

Hufbauer RA, Facon B, Ravigne V, Turgeon J, Foucaud J, Lee CE, Rey O, Estoup A (2012) Anthropogenically induced adaptation to invade (AIAI): contemporary adaptation to human-altered habitats within the native range can promote invasions. Evol Appl 5:89-101. https://doi.org/10.1111/j.1752-4571.2011.00211.x
Hulme PE (2009) Trade, transport and trouble: managing invasive species pathways in an era of globalization. J Appl Ecol 46:10-18. https://doi.org/10.1111/J.1365-2664.2008.01600.X

Iraeta P, Monasterio C, Salvador A, Díaz J (2006) Mediterranean hatchling lizards grow faster at higher altitude: a reciprocal transplant experiment. Funct Ecol 20:865-872. https://doi.org/10.1111/j. 1365-2435.2006.01162.x

Kaiser A, Merckx T, Van Dyck H (2019) Behavioural repeatability is affected by early developmental conditions in a butterfly. Anim Behav 157:219-226. https://doi.org/10.1016/j.anbehav.2019.08. 006

Kelleher SR, Silla AJ, Byrne PG (2018) Animal personality and behavioral syndromes in amphibians: a review of the evidence, experimental approaches, and implications for conservation. Behav Ecol Sociobiol 72:79. https://doi.org/10.1007/ s00265-018-2493-7

Kralj-Fišer S, Schneider JM (2012) Individual behavioural consistency and plasticity in an urban spider. Anim Behav 84:197-204. https://doi.org/10.1016/j.anbehav.2012.04.032

Kruger N, Measey J, Vimercati G, Herrel A, Secondi J (2021) Does the spatial sorting of dispersal traits affect the phenotype of the non-dispersing stages of the invasive frog Xenopus laevis through coupling? Biol J Linn Soc 132:257-269. https://doi.org/10.1093/ biolinnean/blaa191

Kurali A, Pásztor K, Hettyey A, Tóth Z (2018) Resource-dependent temporal changes in antipredator behavior of common toad (Bufo bufo) tadpoles. Behav Ecol Sociobiol 72:91. https://doi.org/10. 1007/s00265-018-2503-9

Lambert MR, Brans KI, Des Roches S, Donihue CM, Diamond SE (2020) Adaptive evolution in cities: progress and misconceptions. Trends Ecol Evol 36:239-257. https://doi.org/10.1016/j. tree.2020.11.002

Lambin EF, Meyfroidt P (2011) Global land use change, economic globalization, and the looming land scarcity. P Natl Acad Sci USA 108:3465-3472. https://doi.org/10.1073/pnas.1100480108

Lande R (2009) Adaptation to an extraordinary environment by evolution of phenotypic plasticity and genetic assimilation. J Evol Biol 22:1435-1446. https://doi.org/10.1111/j.1420-9101.2009. 01754.x

Lenth R, Singmann H, Love J, Buerkner P, Herve M (2018) Emmeans: estimated marginal means, aka least-squares means. https:// CRAN.R-project.org/package $=$ emmeans

Levey DJ, Londoño GA, Ungvari-Martin J, Hiersoux MR, Jankowski JE, Poulsen JR, Stracey CM, Robinson SK (2009) Urban mockingbirds quickly learn to identify individual humans. P Natl Acad Sci USA 106:8959-8962. https://doi.org/10.1073/pnas. 0811422106

Louppe V, Courant J, Videlier M, Herrel A (2018) Differences in standard metabolic rate at the range edge versus the center of an expanding invasive population of Xenopus laevis in the West of France. J Zool 305:163-172. https://doi.org/10.1111/jzo.12548

Lowry H, Lill A, Wong BB (2013) Behavioural responses of wildlife to urban environments. Biol Rev 88:537-549. https://doi.org/10. 1111/brv.12012

Madelaire CB, Barsotti AM, Wagener C, Sugano YYV, Baxter-Gilbert J, Gomes FR, Measey J (2020) Challenges of dehydration result in a behavioral shift in invasive toads. Behav Ecol Sociobiol 74:83. https://doi.org/10.1007/s00265-020-02866-5

Martin LB, Hopkins WA, Mydlarz LD, Rohr JR (2010) The effects of anthropogenic global changes on immune functions and disease resistance. Ann NY Acad Sci 1195:129-148. https://doi.org/10. 1111/j.1749-6632.2010.05454.x

Mazza V, Dammhahn M, Lösche E, Eccard JA (2020) Small mammals in the big city: behavioural adjustments of non-commensal rodents to urban environments. Glob Change Biol 26:6326-6337. https://doi.org/10.1111/gcb.15304 
McCann S, Greenlees MJ, Newell D, Shine R (2014) Rapid acclimation to cold allows the cane toad to invade montane areas within its Australian range. Funct Ecol 28:1166-1174. https://doi.org/10. 1111/1365-2435.12255

Measey J, Davies SJ, Vimercati G, Rebelo A, Schmidt W, Turner A (2017) Invasive amphibians in southern Africa: a review of invasion pathways. Afr Biodivers Conserv 47:a2117. https://doi.org/ 10.4102/abc.v47i2.2117

Mühlenhaupt M, Baxter-Gilbert J, Makhubo BG, Riley JL, Measey J (2021) Growing up in a new world: trait divergence between rural, urban, and invasive populations of an amphibian urban invader. NeoBiota 69:103-132. https://doi.org/10.3897/neobi ota.69.67995

Oliveira FG, Mathias ML, Rychlik L, Tapisso JT, von Merten S (2020) Metabolic and behavioral adaptations of greater white-toothed shrews to urban conditions. Behav Ecol 31:1334-1343. https:// doi.org/10.1093/beheco/araa088

Padayachee AL, Irlich UM, Faulkner KT, Gaertner M, Procheş Ş, Wilson JR, Rouget M (2017) How do invasive species travel to and through urban environments? Biol Invasions 19:3557-3570. https://doi.org/10.1007/s10530-017-1596-9

Padilla P, Courant J, Herrel A (2019) Allocation trade-offs impact organ size and muscle architecture in an invasive population of Xenopus laevis in Western France. J Anat 235:1057-1064. https://doi.org/10.1111/joa.13063

Pautasso M, Dehnen-Schmutz K, Holdenrieder O, Pietravalle S, Salama N, Jeger MJ, Lange E, Hehl-Lange S (2010) Plant health and global change-some implications for landscape management. Biol Rev 85:729-755. https://doi.org/10.1111/j.1469-185X.2010. 00123.x

Peach W, Vincent K, Fowler J, Grice P (2008) Reproductive success of house sparrows along an urban gradient. Anim Conserv 11:493503. https://doi.org/10.1111/j.1469-1795.2008.00209.x

Philpott SM, Albuquerque S, Bichier P, Cohen H, Egerer MH, Kirk C, Will KW (2019) Local and landscape drivers of carabid activity, species richness, and traits in urban gardens in coastal California. Insects 10:112. https://doi.org/10.3390/insects 10040112

Pintor LM, Sih A (2009) Differences in growth and foraging behavior of native and introduced populations of an invasive crayfish. Biol Invasions 11:1895-1902. https://doi.org/10.1007/ s10530-008-9367-2

Pintor LM, Sih A, Bauer ML (2008) Differences in aggression, activity and boldness between native and introduced populations of an invasive crayfish. Oikos 117:1629-1636. https://doi.org/10. 1111/j.1600-0706.2008.16578.x

Putman BJ, Tippie ZA (2020) Big city living: a global meta-analysis reveals positive impact of urbanization on body size in lizards. Front Ecol Evol 8:400. https://doi.org/10.3389/fevo.2020.580745

Pyšek P, Hulme PE, Simberloff D, Bacher S, Blackburn TM, Carlton JT, Dawson W, Essl F, Foxcroft LC, Genovesi P (2020) Scientists' warning on invasive alien species. Biol Rev 95:1511-1534. https://doi.org/10.1111/brv.12627

Ramamonjisoa N, Oiire C, Zheng XJ, Kimura S (2019) Predation decreases cohort foraging activity and growth, yet increases individual size variation in prey. Evol Ecol 33:233-242. https:// doi.org/10.1007/s10682-019-09977-0

Réale D, Reader SM, Sol D, McDougall PT, Dingemanse NJ (2007) Integrating animal temperament within ecology and evolution. Biol Rev 82:291-318. https://doi.org/10.1111/j.1469-185X.2007. 00010.x

Relyea RA (2002) Competitor-induced plasticity in tadpoles: consequences, cues, and connections to predator-induced plasticity. Ecol Monogr 72:523-540. https://doi.org/10.2307/3100055

Relyea RA (2004) Fine-tuned phenotypes: tadpole plasticity under 16 combinations of predators and competitors. Ecology 85:172-179. https://doi.org/10.1890/03-0169
Richardson JM (2001) A comparative study of activity levels in larval anurans and response to the presence of different predators. Behav Ecol 12:51-58. https://doi.org/10.1093/oxfordjournals. beheco.a000378

R Core Team (2020) R: a language and environment for statistical computing. R Foundation for Statistical Computing, Vienna. http://www.r-project.org/index.html. Accessed 8 Nov 2021

Riley JL, Noble DW, Byrne RW, Whiting MJ (2017) Early social environment influences the behaviour of a family-living lizard. R Soc Open Sci 4:161082. https://doi.org/10.1098/rsos.161082

Sargent LW, Lodge DM (2014) Evolution of invasive traits in nonindigenous species: increased survival and faster growth in invasive populations of rusty crayfish (Orconectes rusticus). Evol Appl 7:949-961. https://doi.org/10.1111/eva.12198

Semlitsch RD, Boone MD (2009) Aquatic mesocosms. In: Dodd CK (ed) Amphibian ecology and conservation: a handbook of techniques. Oxford University Press, Oxford, pp 87-104

Sol D, Lapiedra O, González-Lagos C (2013) Behavioural adjustments for a life in the city. Anim Behav 85:1101-1112. https:// doi.org/10.1016/j.anbehav.2013.01.023

Telford NS, Channing A, Measey J (2019) Origin of invasive populations of the Guttural Toad (Sclerophrys gutturalis) on Reunion and Mauritius Islands and in Constantia, South Africa. Herpetol Conserv Biol 14:380-392

Thawley CJ, Kolbe JJ (2020) Artificial light at night increases growth and reproductive output in Anolis lizards. Proc R Soc B 287:20191682. https://doi.org/10.1098/rspb.2019.1682

Thompson MJ, Evans JC, Parsons S, Morand-Ferron J (2018) Urbanization and individual differences in exploration and plasticity. Behav Ecol 29:1415-1425. https://doi.org/10.1093/beheco/ ary 103

Tryjanowski P, Skórka P, Sparks TH, Biaduń W, Brauze T, Hetmański T, Martyka R, Indykiewicz P, Myczko Ł, Kunysz $P$ (2015) Urban and rural habitats differ in number and type of bird feeders and in bird species consuming supplementary food. Environ Sci Pollut Res 22:15097-15103. https://doi.org/ 10.1007/s11356-015-4723-0

Urszán TJ, Garamszegi LZ, Nagy G, Hettyey A, Török J, Herczeg G (2015a) No personality without experience? A test on Rana dalmatina tadpoles. Ecol Evol 5:5847-5856. https://doi.org/ 10.1002/ece3.1804

Urszán TJ, Török J, Hettyey A, Garamszegi LZ, Herczeg G (2015b) Behavioural consistency and life history of Rana dalmatina tadpoles. Oecologia 178:129-140. https://doi.org/10.1007/ s00442-014-3207-0

van Baaren J, Candolin U (2018) Plasticity in a changing world: behavioural responses to human perturbations. Curr Opin Insect Sci 27:21-25. https://doi.org/10.1016/j.cois.2018.02.003

Van Buskirk J (2002) A comparative test of the adaptive plasticity hypothesis: relationships between habitat and phenotype in anuran larvae. Am Nat 160:87-102. https://doi.org/10.1086/ 340599

Vimercati G, Davies SJ, Measey J (2018) Rapid adaptive response to a Mediterranean environment reduces phenotypic mismatch in a recent amphibian invader. J Exp Biol 221:jeb174797. https:// doi.org/10.1242/jeb.174797

Vimercati G, Davies SJ, Measey J (2019) Invasive toads adopt marked capital breeding when introduced to a cooler, more seasonal environment. Biol J Linn Soc 128:657-671. https://doi.org/10.1093/ biolinnean/blz119

Vimercati G, Hui C, Davies SJ, Measey GJ (2017) Integrating age structured and landscape resistance models to disentangle invasion dynamics of a pond-breeding anuran. Ecol Model 356:104116. https://doi.org/10.1016/j.ecolmodel.2017.03.017 
Vincze E, Papp S, Preiszner B, Seress G, Bókony V, Liker A (2016) Habituation to human disturbance is faster in urban than rural house sparrows. Behav Ecol 27:1304-1313. https://doi.org/10. 1093/beheco/arw047

Vitousek PM, D'antonio CM, Loope LL, Rejmanek M, Westbrooks R (1997) Introduced species: a significant component of humancaused global change. New Zeal J Ecol 21:1-16. https://newze alandecology.org/nzje/2008.pdf

Werner E (1988) Size, scaling, and the evolution of complex life cycles. In: Ebenman P, Persson L (eds) Size-structured populations. Springer, Heidelberg, pp 60-81. https://doi.org/10.1007/ 978-3-642-74001-5_6

Westrick SE, Broder ED, Reznick DN, Ghalambor CK, Angeloni L (2019) Rapid evolution and behavioral plasticity following introduction to an environment with reduced predation risk. Ethology 125:232-240. https://doi.org/10.1111/eth.12849

Whitney KD, Gabler CA (2008) Rapid evolution in introduced species, 'invasive traits' and recipient communities: challenges for predicting invasive potential. Divers Distrib 14:569-580. https://doi.org/10.1111/j.1472-4642.2008.00473.x

Wilbur HM (1980) Complex life cycles. Annu Rev Ecol Evol S 11:6793. https://doi.org/10.1146/annurev.es.11.110180.000435
Wilson AD, Krause J (2012a) Metamorphosis and animal personality: a neglected opportunity. Trends Ecol Evol 27:529-531. https:// doi.org/10.1016/j.tree.2012.07.003

Wilson AD, Krause J (2012b) Personality and metamorphosis: is behavioral variation consistent across ontogenetic niche shifts? Behav Ecol 23:1316-1323. https://doi.org/10.1093/beheco/ ars 123

Wright TF, Eberhard JR, Hobson EA, Avery ML, Russello MA (2010) Behavioral flexibility and species invasions: the adaptive flexibility hypothesis. Ethol Ecol Evol 22:393-404. https://doi.org/ 10.1080/03949370.2010.505580

Zuur AF, Leno EN, Elphick CS (2010) A protocol for data exploration to avoid common statistical problems. Methods Ecol Evol 1:3-14. https://doi.org/10.1111/j.2041-210X.2009.00001.x

Publisher's note Springer Nature remains neutral with regard to jurisdictional claims in published maps and institutional affiliations. 